\title{
Erratum to: Characteristics of stable isotope signature of diet in tissues of captive Japanese macaques as revealed by controlled feeding
}

\author{
Rumiko Nakashita $\cdot$ Yuzuru Hamada $\cdot$ \\ Eishi Hirasaki · Juri Suzuki · Toru Oi
}

Published online: 11 June 2013

(C) Japan Monkey Centre and Springer Japan 2013

\section{Erratum to: Primates}

DOI 10.1007/s10329-013-0346-6

Unfortunately, in the original publication of this article, the column heading from the second right in Table 1 has been published incorrectly as " $\delta^{13} \mathrm{~N}(\%)$ ".

It should actually read as " $\delta{ }^{13} \mathrm{C}(\%) "$.

The online version of the original article can be found under doi:10.1007/s10329-013-0346-6.

R. Nakashita $(\bowtie) \cdot$ T. Oi

Wildlife Ecology Laboratory, Forestry and Forest Products

Research Institute, Matsunosato 1, Tsukuba,

Ibaraki 305-8687, Japan

e-mail: nakashita@affrc.go.jp

Y. Hamada · E. Hirasaki

Department of Evolutionary Morphology, Primate Research

Institute, Kyoto University, Inuyama, Aichu 484-8506, Japan

J. Suzuki

Center for Human Evolution Modeling Research,

Primate Research Institute, Kyoto University,

Inuyama, Aichu 484-8506, Japan 